\title{
Water Quality Trading in the Chesapeake Bay
}

Briefing Paper No. 1205 by the Center for Progressive Reform

Rena Steinzor, Nick Vidargas, Shana Jones, and Yee Huang

May 2012

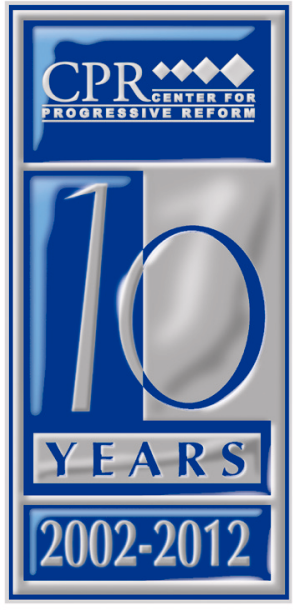




\section{Water Quality Trading in the Chesapeake Bay}

\section{Executive Summary}

Proponents of water quality trading describe it as a silver bullet solution to the severe nutrient pollution that plagues the Chesapeake Bay. At least in theory, trading has two advantages. First, it would allow regulated sources, such as publicly owned treatment works (POTWs), municipal storm sewers, and concentrated animal feeding operations (CAFOs), to spread the considerable costs of cleaning up the Bay's waters among themselves. Second, it would permit those regulated sources to pay unregulated agricultural operations to reduce their nonpoint pollution at a lower cost. Planting buffer crops, prohibiting the application of manure to cropland in the winter, and similar best management practices (BMPs) are less expensive than retrofitting POTWs with pollution control equipment. Because the agricultural sector generates roughly 44 percent of the nitrogen and phosphorus that enters the Bay, ${ }^{1}$ controlling discharges from agriculture is a critical component of any rigorous Bay restoration strategy.

For trading proponents, the timing could not be better. In 2010, the Environmental Protection Agency (EPA) established the Chesapeake Bay Total Maximum Daily Load (TMDL) for nitrogen, phosphorus, and sediment. The Bay TMDL is comprised of separate numerical limits for 92 impaired water segments throughout the Bay Watershed. A water body is impaired if it is sufficiently polluted that it cannot support its "designated use-e.g., drinking, swimming, or boating." Often referred to as a "pollution diet," the Bay TMDL imposes strict limits on the quantities of nitrogen, phosphorus, and sediment and allocates the total permissible amount of each pollutant among the Bay states and the District of Columbia. The Bay states and the District must then make sure that the cumulative total of discharges from all sources does not exceed the limits set by the Bay TMDL, rewriting the permits of regulated sources to reduce their discharges and otherwise creating incentives for unregulated agricultural sources to cut back on their pollution. In response to these tough limits, most Bay states have already begun to plan or implement trading regimes between point and nonpoint sources, and these programs are very likely to expand in the near-term. ${ }^{2}$

EPA and the Bay states face a daunting task, and we understand why they are exploring every possible avenue to success. They confront the TMDL challenge at the same time that severe budget shortfalls undermine their effectiveness. But the federal and Bay state partners cannot afford to adopt a series of solutions that sound good on paper but do not deliver results. Failing again to improve the Bay would destroy their credibility, already undermined because they have a history of taking the easy way outchurning out paper plans but making scant progress on the ground-in past restoration efforts that have fallen far short of expectations over the last three decades.

$\begin{array}{lllllllllllllllllllllllllllll}\text { C } & E & \mathbf{N} & \mathbf{T} & \mathbf{E} & \mathbf{R} & & \mathbf{F} & \mathbf{O} & \mathbf{R} & & \mathbf{P} & \mathbf{R} & \mathbf{O} & \mathbf{G} & \mathbf{R} & \mathbf{E} & \mathbf{S} & \mathbf{S} & \mathbf{I} & \mathbf{V} & \mathbf{E} & & \mathbf{R} & \mathbf{E} & \mathbf{F} & \mathbf{O} & \mathbf{R} & \mathbf{M}\end{array}$




\section{Water Quality Trading in the Chesapeake Bay}

The purpose of this paper is to identify critical elements of an effective trading program. Even if a substantial number of trades are made, the silver bullet will miss its target by a wide margin unless trading programs satisfy these minimal requirements. An equally likely and unfortunate scenario is that agricultural operators will decline the invitation to participate in trading programs, preferring to go about business as usual without sanctioning what they perceive to be quasi-regulation. Under either scenario, implementing unworkable and ineffective trading regimes will only serve to distract policymakers from making the hard choices necessary to ensure real and lasting gains. Trading is a means, not an end. If it fails, it should go. Bay states should be prepared with contingency plans should trading markets fail to perform as expected, including plans to implement mandatory programs for agricultural reductions to achieve the Bay TMDL if pollution reductions fall behind schedule.

An industry lawsuit challenging the Bay TMDL is pending as this paper is written, and a legal challenge to trading by an environmental group is possible. We do not address the merits of either lawsuit here. Instead, this paper assumes that the Bay states and the District of Columbia will proceed, full speed ahead, with the design and attempted implementation of trading and offsetting regimes.

The Bay states are not the first to deploy a water quality trading regime and would benefit from a careful study of the lessons from other states that have experimented with such initiatives. Especially when trading involves unregulated nonpoint sources, state and local officials have expended substantial resources only to discover that unregulated agricultural sources refuse to participate. ${ }^{3}$ U.S. Department of Agriculture (USDA) economists point out, for example, that of 15 trading programs that promote trades between point sources and agricultural nonpoint sources, only four have experienced any trades and just two have experienced more than a handful. 4 These experiences underscore the danger that Bay states will become unduly preoccupied with the implementation of trading regimes that fail for lack of agricultural participants, causing them to miss their milestones for reducing pollution and fall far behind in meeting the Bay TMDL's long-term goals.

Our recommendations are grouped into two categories: (1) measures necessary to ensure that trading does not undermine public health and environmental quality and (2) program elements that ensure the integrity and effectiveness of trading so that such regimes do not foster fraud or fail to deliver expected environmental benefits.

$\begin{array}{llllllllllllllllllllllllllllll}C & \mathbf{E} & \mathbf{N} & \mathbf{T} & \mathbf{E} & \mathbf{R} & & \mathbf{F} & \mathbf{O} & \mathbf{R} & \mathbf{P} & \mathbf{R} & \mathbf{O} & \mathbf{G} & \mathbf{R} & \mathbf{E} & \mathbf{S} & \mathbf{S} & \mathbf{I} & \mathbf{V} & \mathbf{E} & & \mathbf{R} & \mathbf{E} & \mathbf{F} & \mathbf{O} & \mathbf{R} & \mathbf{M}\end{array}$




\section{Water Quality Trading in the Chesapeake Bay}

\section{Recommendations}

\section{Protecting Public Health and the Environment}

As the experience of other states demonstrates, a successful trading regime depends on robust demand for credits. Only strong regulations can stimulate such demand. Therefore, federal and state regulators must remain committed to achieving nutrient reductions by using traditional regulatory controls. A trading program cannot succeed if it is implemented in the absence of regulatory standards.

Although Congress seems currently incapable of updating major environmental laws, we must nevertheless emphasize the importance of extending the Clean Water Act (CWA) to cover nonpoint sources. The best hope for successful trading is to give all of the sources that contribute to the Bay's pollution crisis equal incentive to participate in distributing the costs of reductions more efficiently.

Government regulators must prevent the formation of "hot spots," or localized concentrations of nutrients, that threaten public health or the environment in particular areas. Regulators should implement geographic restrictions on downstream, interbasin, and interstate trades unless the segment into which the buyer discharges meets water quality standards. They should also require credit buyers to cease discharges if the discharges for which credits are purchased lead to the formation of hot spots. Finally, regulators must consider environmental justice concerns and vulnerable communities that may be affected by new or increased pollutant discharges.

To compensate for the uncertainties caused by unreliable technologies for measuring the results of BMPs designed to reduce pollution, trading regimes must incorporate measures to prevent excessive pollutant loads, such as requiring at least two units of nonpoint source reductions for every one unit of point source reduction credited.

\section{Monitoring and Oversight to Avoid Waste, Fraud, and Abuse}

Bay states already lack the resources they need for traditional enforcement. Creating a viable trading market poses different challenges, but it will be no less demanding in terms of resources. Indeed, accountability for trading could easily be shortchanged without additional funding and staffing. EPA should exercise its oversight authority under the CWA to ensure that trading programs help Bay states to achieve water quality standards and the Bay TMDL. A trading program must be monitored and must achieve its targets. EPA should ensure that Bay states' trading programs meet at a minimum the guidelines established in its Water Quality Trading Policy (2003), previous letters to Bay states, and most importantly Appendix S of the Bay TMDL. ${ }^{5}$

$\begin{array}{llllllllllllllllllllllllllllll}C & \mathbf{E} & \mathbf{N} & \mathbf{T} & \mathbf{E} & \mathbf{R} & & \mathbf{F} & \mathbf{O} & \mathbf{R} & \mathbf{P} & \mathbf{R} & \mathbf{O} & \mathbf{G} & \mathbf{R} & \mathbf{E} & \mathbf{S} & \mathbf{S} & \mathbf{I} & \mathbf{V} & \mathbf{E} & & \mathbf{R} & \mathbf{E} & \mathbf{F} & \mathbf{O} & \mathbf{R} & \mathbf{M}\end{array}$




\section{Water Quality Trading in the Chesapeake Bay}

\section{Appendix S of the Bay TMDL: EPA Requirements that Must Be Met and Implemented}

EPA directly addresses the use of offsets for new and expanded discharges in Section 10 and Appendix S of the Bay TMDL. EPA expects Bay states to completely offset new and expanded discharges that are not specifically accounted for in the Bay TMDL. Appendix S contains a list of "common elements" that EPA "encourages and expects" Bay states to use for offset and trading programs. Unfortunately, throughout its discussion of trading and offset programs, EPA explicitly states that Appendix $S$ and the recommendations in Section 10 are not mandatory regulatory requirements. Because the agency itself recognizes "the value that consistent offset programs will have in promoting effective regional implementation of the [Bay] TMDL," EPA should mandate that at a minimum Bay states adopt these common elements before their trading programs go forward.

Among the most important elements:

- States must require that point sources first meet their "technology-based effluent limits" (TBEL) prior to using credits for trading or offsets. Point sources should only be permitted to purchase credits to achieve the more stringent "water quality based effluent limits" (WQBEL) needed to restore water quality. The CWA mandates that point sources use a sector-wide standard of TBELs limits. If those TBELs are insufficient to meet water quality standards, a secondary set of water quality-based effluent limits goes into effect, along with the requirement to establish a TMDL. In the Bay, states must ensure that all point sources meet their TBEL and have installed the required technology prior to purchasing any credits. Trading cannot be used to meet TBELs.

States must ensure that permit writers incorporate trading transactions into the National Pollutant Discharge Elimination System (NPDES) permits held by point sources seeking to buy or sell credits. WQBELs based on WLAs should also be incorporated into permits. This element is important because the terms and conditions in NPDES permits are enforceable by EPA and states, as well as by citizens through the CWA's citizen suit provision.

States must ensure that nonpoint sources meet a minimum baseline, such as a suite of BMPs, before they are permitted to generate and sell credits. Baselines should be carefully calibrated to meet the TMDL sector load allocation and be strict enough that the total reductions will be significant but leave sufficient room to allow for trading to be profitable.

- States must protect vulnerable communities from disproportionate impacts arising from trading. This is EPA's most explicit support for considering environmental justice in trading. States should ensure that disproportionate impacts are considered and avoided.

EPA should also strengthen its guidance as part of its oversight authority under the CWA. For example, the agency should consider retracting its support for interstate trading in Section 10 of the Bay TMDL. Proposed interstate and interbasin trading raises concerns about the consistency of state programs and the likelihood of these trades to rely on the least stringent requirements. EPA should also strictly adhere to section 122.4 of the CWA regulations and enforce restrictions on trading in impaired waters.

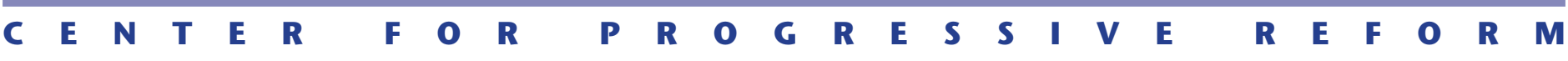




\section{Water Quality Trading in the Chesapeake Bay}

\section{Recommendations (continued)}

The Bay TMDL creates an enforceable limit on total discharges, but it could be undermined by fraud and the uncertain performance of certain agricultural BMPs used to achieve pollutant reductions. These reductions must be real, not simply phantom savings generated by dubious accounting methods. To ensure accountability, federal regulators should mandate that:

(1) Bay states adopt numeric nutrient criteria for nitrogen and phosphorus as objective, quantitative, and measurable markers of success or failure to achieve pollution reductions;

(2) Bay states conduct comprehensive, in-stream water quality monitoring to ensure that actual reductions occur as a result of trading programs;

(3) Trading program participants submit periodic, standardized reports on their discharges, trades, pollution-reducing, and credit-generating activities to ensure that trading programs generate the promised pollution reductions; and

(4) All trades and periodic reports are made available online.

EPA and Bay states should ensure that trades are enforceable by either incorporating trade terms into the NPDES permit of a regulated point source or memorializing the trade terms in a contract that allows EPA or the state to enforce the contract as a third-party beneficiary.

Ultimately, a trading program cannot be implemented on a shoestring budget. EPA and Bay states should plan for the necessary financial, technical, and personnel resources needed to monitor and oversee trading programs for the long-term.

$\begin{array}{llllllllllllllllllllllllllllllllll}C & \mathbf{E} & \mathbf{N} & \mathbf{T} & \mathbf{E} & \mathbf{R} & & \mathbf{F} & \mathbf{O} & \mathbf{R} & & \mathbf{P} & \mathbf{R} & \mathbf{O} & \mathbf{G} & \mathbf{R} & \mathbf{E} & \mathbf{S} & \mathbf{S} & \mathbf{I} & \mathbf{V} & \mathbf{E} & & \mathbf{R} & \mathbf{E} & \mathbf{F} & \mathbf{O} & \mathbf{R} & \mathbf{M}\end{array}$




\section{Water Quality Trading in the Chesapeake Bay}

\section{Introduction}

Restoration of the Chesapeake Bay has reached a turning point. EPA's development of the Bay TMDL is the most promising forward progress in the past few decades, and states and local governments have done much work to develop implementation plans to meet the pollution diet. Faced with the pressure to address pollution from nonpoint sources, water quality trading has emerged as a favored option for some policymakers and Bay advocates because it creates a financial incentive for those sources to voluntarily reduce pollution. If participation is widespread, significant reductions in nutrients are possible.

An environmentally sound water quality trading program is more complicated in practice than it is on paper, though. For example, the technical and financial resources to measure and monitor nonpoint source pollution reductions still fall short, rendering uncertain the actual amount of reductions claimed as part of a trade. Poor and inadequate enforcement against point sources can lead to weak demand and a failure to improve water quality. And, if regulators fail to prevent fraudulent transactions or allow overly permissive credit banking, the Bay TMDL's firm limit on pollution could easily become undermined and meaningless. Bay states that promote trading can avoid some of these harder challenges by instituting less stringent rules, but they risk the possibility that uncontrolled or underregulated trading will not improve water quality in the Bay, or even contribute to further degradation.

The primary goal of a trading program should be to meet water quality standards and to improve overall water quality. We therefore examine trading from the perspective of accountability, asking what is necessary to make such a program actually achieve its water quality objectives. After providing a brief overview of water quality trading programs, we make basic recommendations to continue using traditional regulatory tools, to establish a set of minimum criteria, and to ensure resources for the long term. We then detail the basis for an accountability framework, built on the pillars of monitoring and verification, protecting human health and the environment, and enforcement and oversight.

\section{Proceed with Caution: The Mismatch between Trading on Paper and in Practice}

\section{Trading Programs: How the Markets Work on Paper}

Environmental markets align a community of buyers that are legally obligated to meet a certain environmental standard with sellers that can meet this standard at a significantly lower cost. With the Bay TMDL, the potential buyers include the regulated point sources that face requirements to further reduce pollution discharges and fully offset new or expanded discharges. The potential sellers are some point sources but mostly nonpoint

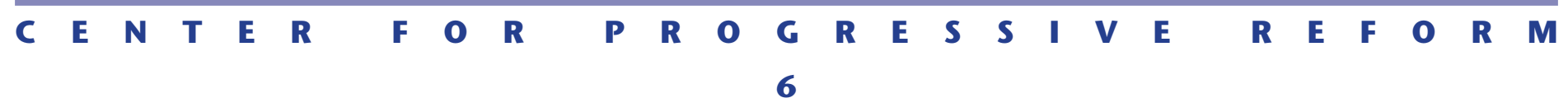




\section{Water Quality Trading in the Chesapeake Bay}

sources-largely unregulated agricultural operations-that face few, if any, mandatory requirements to reduce their discharges. By reducing their runoff, the sellers generate credits that the buyers purchase, resulting in a "win-win" solution: the regulated point sources achieve their pollution reductions, the nonpoint sources have an incentive to reduce their pollution, and the cumulative reductions help states to achieve the Bay TMDL.

\section{The Market Driver}

The World Resources Institute (WRI) estimates that a municipality required to reduce nutrient-rich stormwater effluent would face a cost of over $\$ 200$ per pound of annual nitrogen reduction. With nutrient trading, the municipality could pay an agricultural operator to plant winter cover crops instead, at a cost of just $\$ 4.70$ per pound of annual nitrogen reduction. On paper, this exchange sounds ideal: The agricultural operator earns a premium for behavior society would like to encourage in the first place, the regulated polluter achieves compliance with its permit, and nutrient levels in the waterway are reduced dramatically. However, in practice, water quality trading has not yet been the success that proponents have imagined.

See Cy Jones, et al., World Resources Institute, How Nutrient Trading Could Help Restore the ChesAPEAKE BAY (2010), available at http://pdf.wri.org/working_papers/ how_nutrient_trading_could_help_restore_the_chesapeake_bay.pdf

\section{Trading Programs: How the Markets Fail in Practice}

The lack of sufficient supply and demand, the two most basic and necessary components of a market, is the major reason that water quality trading programs have not succeeded in reducing nutrient pollution. A strong regulatory driver and the threat of enforcement generate demand for credits, and the lack thereof can doom trading programs. Because regulated sources must meet an enforceable pollution limit, trading becomes a cost-effective tool for them to meet their legal obligations or a profitable way to sell credits for pollution reductions below their limits. At the same time, point sources may have concerns about equity when they see nonpoint sources profiting from trading while point sources alone must bear the burden of regulation.

On the supply side, nonpoint sources lack strong legal obligations to control their pollution and thus lack a crucial driver to participate in the marketplace. The financial incentive to generate and sell credits must therefore overcome obstacles to initial participation and account for other concerns. For example, trading programs often require sellers to first meet baseline pollutant reductions and to generate an additional reserve of credits to account for the inherent uncertainty in quantifying pollution reductions from agricultural lands. Ultimately, some nonpoint sources may decide that the profit potential is insufficient to justify participating in the market.

$\begin{array}{llllllllllllllllllllllllllllllll}\mathbf{C} & \mathbf{E} & \mathbf{N} & \mathbf{T} & \mathbf{E} & \mathbf{R} & & \mathbf{F} & \mathbf{O} & \mathbf{R} & \mathbf{P} & \mathbf{R} & \mathbf{O} & \mathbf{G} & \mathbf{R} & \mathbf{E} & \mathbf{S} & \mathbf{S} & \mathbf{I} & \mathbf{V} & \mathbf{E} & & \mathbf{R} & \mathbf{E} & \mathbf{F} & \mathbf{O} & \mathbf{R} & \mathbf{M}\end{array}$




\section{Water Quality Trading in the Chesapeake Bay}

Agricultural nonpoint sources may also be reluctant to participate in a system that requires them to explicitly acknowledge their contribution to pollution or to accept additional oversight of their businesses. They may be concerned that their voluntary participation now may lead to "a credible basis for justifying future restrictions on their emissions that could result in significant long-term costs later.”

At a more fundamental level, the value and quality of credits are difficult to measure and guarantee. This lack of certainty can open the door to fraudulent, overstated, and underperforming trades and undermine progress toward improving water quality. To avoid paper trades or minimally functional trades, oversight is absolutely necessary to enforce regulatory requirements, prevent gaming of the system, and otherwise protect the public interest that is often ignored in environmental markets. Absent this oversight, the prospects for water quality credit markets to prevent declining water quality are dim.

\section{Aligning Trading Programs on Paper and in Practice: Overarching Recommendations}

The simple truth is that water quality trading has not met expectations in other parts of the country. Although EPA has supported more than 50 water quality trading programs nationwide, few of these programs genuinely function because of design and implementation problems. ${ }^{7}$ For example, USDA economists have found that, of 15 trading programs that promote trades between point sources and agricultural nonpoint sources, only four have experienced any trades, and just two have experienced more than a handful. ${ }^{8}$ Given this track record, policymakers should proceed with caution before scarce government resources are poured into programs that do not deliver the reductions required by the Bay TMDL. At the most basic level:

Federal and state regulators must remain committed to achieving nutrient reductions by using traditional regulatory controls in addition to trading programs and outlining contingency plans to reduce pollution if trading does not produce the expected reductions. The cost savings promised by trading advocates are important but alone cannot justify the adoption of trading in lieu of traditional pollution controls and infrastructure improvements. A strong regulatory driver and the threat of enforcement bring buyers and sellers to the table and are critical to any successful, robust environmental trading program.

EPA should also require Bay states to develop contingency plans that specifically address how nutrients will be reduced if trading does not work or does not produce as many reductions as expected. For example, a contingency plan could limit trades from nonpoint sources or increase trading ratios. The Bay states could also implement mandatory regulations for agriculture if trading programs fail, as Delaware, Maryland, and Virginia have stated in their Watershed Implementation Plans.

$\begin{array}{llllllllllllllllllllllllllll}\text { C } & E & \mathbf{N} & \mathbf{T} & \mathbf{E} & \mathbf{R} & & \mathbf{F} & \mathbf{O} & \mathbf{R} & \mathbf{P} & \mathbf{R} & \mathbf{O} & \mathbf{G} & \mathbf{R} & \mathbf{E} & \mathbf{S} & \mathbf{S} & \mathbf{I} & \mathbf{V} & \mathbf{E} & \mathrm{R} & \mathbf{E} & \mathbf{F} & \mathbf{O} & \mathbf{R} & \mathbf{M}\end{array}$




\section{Water Quality Trading in the Chesapeake Bay}

EPA should ensure that trading programs in the Bay meet the minimum guidelines established in its Water Quality Trading Policy (20o3), previous letters to Bay states, and most importantly Section 10 and Appendix $S$ of the Bay TMDL.9 While EPA's guidance is not a regulatory document and instead provides basic, broad outlines for how Bay states should think about trading, it nevertheless provides some recommendations that should serve as minimum requirements for trading in the Bay. Appendix S of the Bay TMDL establishes a stronger set of "common elements" that EPA expects to see with respect to offsetting new or increased nitrogen, phosphorus and sediment loadings. EPA should evaluate whether proposed programs meet these elements both on paper and in practice.

\section{EPA and the Bay states should ensure resources for the long term.} The Bay states are frighteningly low on resources for traditional enforcement of environmental laws. Trading will require substantial additional funding and staffing in order to adequately monitor the market, but those resources do not exist. For example, the Maryland Department of the Environment has concluded in every year since 2007 that the agency is significantly underfunded to fulfill its basic mission. ${ }^{10}$ Between 2000 and 2009, overall funding for the enforcement workforce of the Water Management Administration (WMA) declined nearly 25 percent when adjusted for inflation and coincided with a doubling of pollutant-discharge permits in effect. During the same period, the number of active, full-time inspectors in the WMA also decreased by 25 percent. The funding picture for other states is hardly any better. ${ }^{11}$

EPA and the Bay states should plan for and ensure the long-term availability of resources for enforcement and oversight of trading.

$\begin{array}{lllllllllllllllllllllllllllll}\text { C } & E & \text { N } & \text { T } & \text { E } & \text { R } & & \text { F } & \mathbf{O} & \mathbf{R} & & \mathbf{P} & \mathbf{R} & \mathbf{O} & \mathbf{G} & \mathbf{R} & \mathbf{E} & \mathbf{S} & \mathbf{S} & \mathbf{I} & \mathbf{V} & \mathbf{E} & \mathrm{R} & \mathbf{E} & \mathbf{F} & \mathbf{O} & \mathbf{R} & \mathbf{M}\end{array}$




\section{Water Quality Trading in the Chesapeake Bay}

\section{Lessons from Another Media: \\ Trading in the Clean Air Act's Acid Rain Program}

The Acid Rain Program is often cited as an unmitigated success that provides the paradigm for expanding trading programs to other pollutants and media. Yet the reasons why sulfur dioxide trading achieved its goals are too often overlooked. They include:

The acid rain trading program was established in the 1990 Clean Air Act Amendments, which made critical threshold decisions such as the initial allocation of pollution credits, leaving EPA free to focus on eliminating waste, fraud, and abuse from the system. Clear and unquestionable threshold rules simplify program implementation by reducing legal and technical uncertainty and articulating the costs of inaction or noncompliance.

The program was premised on continuous emissions monitoring for each and every coal-fired power plant that participated in the program, thereby assuring that trading was based on accurate estimates of future emissions. The Acid Rain Program benefitted from some of the most rigorous and complete emissions data ever collected by a government agency. Regulators built on a pre-existing and well-developed regulatory regime under the Clean Air Act that enabled extensive monitoring, reporting, and verification, as well as rigorous data quality analysis. Because all sources had installed continuous emissions monitoring, baseline data went back several years.

Hard caps on total emissions and strong enforcement create robust demand for credits and encourage innovative pollution reduction techniques. Strong caps, clear consequences, and increasingly punitive penalties create incentives strong enough to drive robust demand. In the Acid Rain Program, excess emissions automatically triggered significant economic penalties in addition to being deducted from a facility's allowances. Regulators also set a sufficiently low cap to ensure demand would be strong.

Wigh concentrations of $\mathrm{SO}_{2}$ that resulted from episodic trades did not pose a threat to public health and the environment. The hot spot problem - that is, accumulation of dangerous levels of pollution as a direct result of trading - was not a problem in the acid rain trading program because $\mathrm{SO}_{2}$ had attenuated, not acute, local effects.

Unfortunately, none of these conditions apply to water quality trading in the Chesapeake Bay at the moment. Monitoring technology is primitive at best, hot spots are a real threat, and the uncertainty inherent in BMP implementation could undermine the cap established by the Bay TMDL.

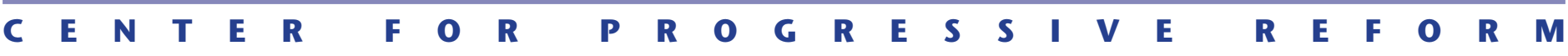




\section{Water Quality Trading in the Chesapeake Bay}

\section{Principles for Accountability in Trading: Comprehensive Design, Environmental Equity, and Rigorous Enforcement}

Water quality trading markets that lack real accountability are unlikely to succeed in achieving the Bay TMDL or making any real progress towards water quality improvements. Policymakers can look to three overarching principles to support truly accountable trading programs in the Chesapeake. First, EPA and the Bay states can ensure that the Bay TMDL drives real pollution reductions by focusing on robust design elements like monitoring, verification, and the use of trading ratios. Second, the Bay states and EPA must focus on avoiding hot spots and promoting environmental equity. Finally, the Bay states and EPA must commit to effective oversight and enforcement.

Principle I: A rigorous, accountable trading program ensures the Bay TMDL drives real pollution reductions through robust monitoring and verification.

In the rush to establish trading programs, EPA and the Bay states have so far failed to adopt mechanisms to quantify, monitor, verify, and track nutrient reductions and trades. Without these key mechanisms, neither federal or state officials nor the public will be able to determine whether trading results in nutrient reductions. Trading programs may become vulnerable to fraud that could undermine the Bay TMDL. For example, without verifying whether certain practices are actually implemented and reduce nutrient runoff or without gathering in-stream monitoring data, trading programs may produce a flurry of activity on paper but ultimately fail to help states achieve the Bay TMDL.

The following recommendations help to ensure that trading programs do not undermine the firm cap set by the Bay TMDL and are credible, fair, and ultimately lead to real improvements in water quality.

Bay states should adopt numeric nutrient criteria specifically for nitrogen and phosphorous as clear markers of success or failure to reduce pollution and therefore objective measures of accountability.

Under the CWA, states are required to establish broad water quality standards that consist of two main components: a designated use and water quality criteria. ${ }^{12}$ The designated use identifies for what purposes the water body will be used, such as drinking water, recreational, or industrial use. Water quality criteria establish the chemical, biological, nutrient, and sediment composition of a water body and requires their levels to support the designated use. Water quality criteria can be numeric for toxic pollutants such as arsenic or narrative for other pollutants, including nutrients. ${ }^{13}$ However, in 1998 EPA established a policy to strongly encourage all states to develop numeric nutrient criteria. ${ }^{14}$

$\begin{array}{lllllllllllllllllllllllllllllll}C & E & N & \mathbf{T} & \mathbf{E} & \mathbf{R} & & \mathbf{F} & \mathbf{O} & \mathbf{R} & \mathbf{P} & \mathbf{R} & \mathbf{O} & \mathbf{G} & \mathbf{R} & \mathbf{E} & \mathbf{S} & \mathbf{S} & \mathbf{I} & \mathbf{V} & \mathbf{E} & & \mathbf{R} & \mathbf{E} & \mathbf{F} & \mathbf{O} & \mathbf{R} & \mathbf{M}\end{array}$




\section{Water Quality Trading in the Chesapeake Bay}

A narrative water quality standard is not a black-and-white test but instead an extremely subjective evaluation. Among the Bay states, only New York and Virginia have adopted numeric nutrient criteria and only for a few water bodies. The remaining Bay states rely on narrative criteria. ${ }^{15}$ Although the numeric allocations in the Bay TMDL are a significant first step, numeric nutrient criteria further promote accountability by establishing a clear threshold of the concentration of nutrients in the Bay that is measurable. The Bay TMDL is indisputably an important tool for reducing pollution, but it is only a measure of how much pollution is entering the Bay. A numeric measurement of the concentrations of pollutants actually in the water is more accurate.

The table below demonstrates the objective nature of numeric criteria compared to the subjective nature of narrative criteria.

\begin{tabular}{|c|c|}
\hline NUMERIC ${ }^{16}$ & NARRATIVE \\
\hline $\begin{array}{l}\text { "For the protection of human health against } \\
\text { the ingestion of contaminated water and } \\
\text { contaminated aquatic organisms: The } \\
\text { ambient water quality criterion for cadmium is } \\
\text { recommended to be identical to the existing } \\
\text { drinking water standard, which is } 10 \mu \mathrm{g} / \mathrm{L} \\
\text { (micrograms per liter)." }\end{array}$ & $\begin{array}{l}\text { "The waters of [Maryland] may not be } \\
\text { polluted by any material... attributable to } \\
\text { sewage, industrial waste, or other wastes in } \\
\text { amounts sufficient to be unsightly, produce } \\
\text { taste or color, [or] change the color to } \\
\text { produce objectionable color for aesthetic } \\
\text { purposes."17 }\end{array}$ \\
\hline
\end{tabular}

Bay states should require comprehensive, in-stream water quality monitoring to ensure that actual reductions occur as a result of trading programs.

A trading program that succeeds in meeting water quality standards begins with high quality and accurate real-time data, which in turn requires substantial monitoring and measurement efforts. Monitoring is required because it indicates that pollution is (or is not) actually being reduced, apart from what models may project. For example, the oft-cited successful acid rain trading program depended in large measure on the ubiquitous use of "continuous emissions monitoring" that was extraordinarily reliable in quantifying emissions. No comparable mechanism exists for gauging the reductions achieved by the BMPs used to reduce nutrient loading, especially from nonpoint sources.

An expansive monitoring network enables effective oversight by regulatory agencies, allowing regulators to identify all sources of nutrients to the Bay and quickly locate and address hot spots. Accomplishing those goals helps promote accountability by expanding the universe of information and improving the efficacy of the marketplace. A strong monitoring program should comprehensively gather data, track nutrients, and identify sources of pollution to the Bay. Measuring discharges from point sources and relying on ratios or models for nonpoint source discharges will not be sufficient to ensure that trading programs are accountable.

$\begin{array}{llllllllllllllllllllllllllllll}C & E & N & \mathbf{N} & \mathbf{E} & \mathbf{R} & & \mathbf{F} & \mathbf{O} & \mathbf{R} & \mathbf{P} & \mathbf{R} & \mathbf{O} & \mathbf{G} & \mathbf{R} & \mathbf{E} & \mathbf{S} & \mathbf{S} & \mathbf{I} & \mathbf{V} & \mathbf{E} & & \mathbf{R} & \mathbf{E} & \mathbf{F} & \mathbf{O} & \mathbf{R} & \mathbf{M}\end{array}$




\section{Water Quality Trading in the Chesapeake Bay}

EPA and Bay states should require independent, rigorous, and transparent verification of nutrient reductions.

EPA, Bay states, and even universities or other organizations should develop reliable scientific and technical tools to verify that actual reductions are occurring in practice and to better assess the effectiveness of pollution reduction actions. Trading programs that can effectively verify nutrient reductions and compliance with trade agreements are accountable because they can show actual pollution reductions are occurring. The USDA's Nitrogen Trading Tool is an example of one model, but it is in the prototype stage. ${ }^{18}$

Verification should be conducted by individuals or organizations with no conflicts of interest. In Pennsylvania, for example, verification is being conducted by entities that may have conflicts of interest-agricultural consultants with pre-existing relationships with agricultural concerns, for example. Fraud will remain a very urgent concern in water quality trading, highlighting the need for both comprehensive water quality monitoring and accurate and independent verification.

\section{The Problem with Verifying Implementation: An Example}

One of the major obstacles to trading is quantifying pollution reductions from credit sellers such as agricultural operators and other nonpoint sources. Because the very nature of pollution from these sources is diffuse, the inability to quantify pollution reductions and therefore verify that the reductions have occurred threaten to undermine the quality of trading credits. The risk of giving excess credit or trading paper credits for unquantified and unverified activities increases, and the Bay would continue to suffer.

EPA, the USDA, and Bay states all provide cost share funding for certain BMPs that are intended to reduce nutrient and sediment runoff from agricultural lands. However, spot-checks for implementation are low. For example, in Virginia only 5 percent of each type of BMP is inspected. Such a low rate is inadequate to verify pollutant reductions, both for trading purposes and for achieving the Bay TMDL

EPA and Bay states should require trading program participants to submit periodic, standardized reports on their discharges, trades, pollutionreducing, and credit-generating activities to ensure that trading programs generate the promised pollutant reductions.

Self-reporting by the regulated community is at the core of many environmental statutes and is essential to accountability in trading. It places part of the onus of regulation on the polluters themselves and maximizes public resources for regulators to conduct inspections and enforcement actions. Reporting also increases the information available to regulators and the public to prioritize and improve oversight and enforcement.

$\begin{array}{llllllllllllllllllllllllllllll}C & \mathbf{E} & \mathbf{N} & \mathbf{T} & \mathbf{E} & \mathbf{R} & & \mathbf{F} & \mathbf{O} & \mathbf{R} & \mathbf{P} & \mathbf{R} & \mathbf{O} & \mathbf{G} & \mathbf{R} & \mathbf{E} & \mathbf{S} & \mathbf{S} & \mathbf{I} & \mathbf{V} & \mathbf{E} & & \mathbf{R} & \mathbf{E} & \mathbf{F} & \mathbf{O} & \mathbf{R} & \mathbf{M}\end{array}$




\section{Water Quality Trading in the Chesapeake Bay}

All sources in the Bay should be required to submit annual and quarterly selfreports on discharges, soil and nutrient management practices, and abatement efforts using tools like the discharge monitoring reports already required of permitted point sources. Each report should detail the terms of the trade, including the nature of the discharges being offset, baseline verification, and financial assurances. If Bay states use aggregators or exchanges to facilitate trades, credit generators should be required to submit details of their credit generating activities, including verification plans, in their proposals. EPA and Bay states should make these reports available to the public.

Bay states should establish transparent markets by making trading data public.

EPA and Bay states should ensure that trading markets are transparent by publicly disclosing trading data and information. Transparency allows for better public oversight, fosters trust in the markets themselves, and enables faster resolution of environmental and equity problems. For example, to determine whether the sellers of credits are implementing promised pollutant reductions, EPA and Bay states must be able to monitor compliance with trade agreements and permit conditions. Only by measuring water quality can regulators tell whether pollutant limits are being met. Data should be widely and publicly shared, including periodic reporting, which must be required for all sources and all trades.

A key tool to both ensuring accountability and promoting fair environmental outcomes is to allow public access to the data and information used to support and design trading programs. This basic level of transparency can help to build support among all citizens and stakeholders for investing scant public resources in trading markets.

To promote transparency, EPA and Bay states should collect information such as:

data on the number and identity of trading entities subject to trading compliance audits, out of compliance with both regulatory requirements and trading agreements, and the success of enforcement efforts;

maps of trading boundaries and areas, sources of pollution, and where credits are generated and used;

the market value of a credit;

- for individual trades: nutrient management plans, soil conservation plans, monitoring reports, and all trade and credit tracking documentation.

To facilitate tracking, public information should then be electronically stored and easily available in a single place online, such as the existing Bay Tracking and Accountability System (BayTAS). ${ }^{19}$

$\begin{array}{llllllllllllllllllllllllllllll}C & \mathbf{E} & \mathbf{N} & \mathbf{T} & \mathbf{E} & \mathbf{R} & & \mathbf{F} & \mathbf{O} & \mathbf{R} & \mathbf{P} & \mathbf{R} & \mathbf{O} & \mathbf{G} & \mathbf{R} & \mathbf{E} & \mathbf{S} & \mathbf{S} & \mathbf{I} & \mathbf{V} & \mathbf{E} & & \mathbf{R} & \mathbf{E} & \mathbf{F} & \mathbf{O} & \mathbf{R} & \mathbf{M}\end{array}$




\section{Water Quality Trading in the Chesapeake Bay}

To ensure that water quality trading leads to improved water quality, and to account for uncertainties, EPA and Bay states should design trading programs with ratios greater than $1: 1$ to account for the uncertainties in measuring, monitoring, and applying trading credits and to promote water quality improvements.

Trading ratios account for a number of challenges that are relevant to achieving water quality goals by requiring that buyers purchase more credits than they require to achieve their discharge allocations. Because even the best trading regime is unlikely to result in the necessary reductions, and because uncertainties will remain about the precise extent of reductions made, credit sellers should be required to produce more reductions than they sell. The trading ratio is an important tool for any water quality trading program because it can compensate for uncertainty in the effectiveness of BMPs in reducing pollutant runoff as well as differences in hydrology and geography between trading partners. Because trading ratios make credits more expensive, as Bay states develop numeric water quality criteria and scientific research provides more certainty in quantifying and measuring discharge reductions, the uncertainty portion of ratios may be adjusted downwards.

\section{Restrictions on New Permits in Impaired Waters and Pinto Creek}

Within the Chesapeake Bay watershed, 89 of 92 segments are classified as impaired for nutrients. New permits for discharges into impaired waters are addressed by 40 C.F.R. 122.4, which requires permit applicants to show that (1) existing loading in the segment leaves room for additional discharges without violating the TMDL and (2) existing discharges are subject to compliance schedules that will achieve the water quality standards for that water body.

In the 2007 case Friends of Pinto Creek v. EPA, the Ninth Circuit Court of Appeals ruled this regulation requires strict adherence to these conditions and that a trading program cannot circumvent them. The decision neither translates into a complete prohibition on new permits for new discharges into impaired waters, nor does it constitute an outright prohibition on trading programs.

Pinto Creek does provide a measure of accountability, though, and leverage for EPA to put sources on enforceable schedules to meet the Bay TMDL if state trading programs go forward. For example, the Ninth Circuit interpreted the phrase "all dischargers" to include both point sources and nonpoint sources. Under the ruling, both categories must be on track to meet water quality standards before EPA or a state issues new permits.

EPA has suggested in Section 10 and Appendix S of the Bay TMDL that offsetting new and expanded discharges is a priority for the agency. EPA and Bay states should also commit to following Pinto Creek and not issue a permit if a new or expanded discharge will cause or contribute to a violation of water quality standards in an impaired water body.

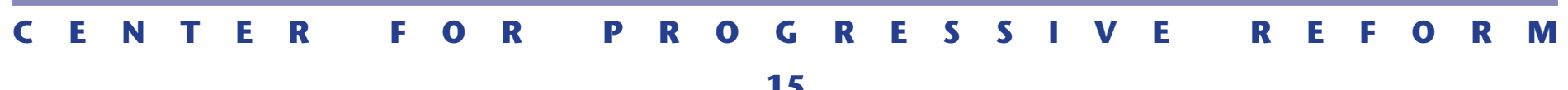




\section{Water Quality Trading in the Chesapeake Bay}

To achieve the Bay TMDL, water quality trading programs should avoid 1:1 trading ratios, with very few exceptions such as point-source-to-point-source trades where the certainty of reductions is high and no other monitoring or geographic issues are present. Poorly designed or overly simplified ratios facilitate trades at the expense of environmental protection. Ratios will ultimately depend on trading partners and may have to be established on a case-by-case basis, with general principles available for predictability.

\section{Principle 2: A rigorous, accountable trading program protects human health and the environment by avoiding the creation of hot spots and other environmental harms and inequities.}

Trading that leads to environmental inequities is fundamentally unfair to the people who live and work or draw drinking water near that segment of the watershed near that segment of the watershed. In some parts of the Chesapeake, watermen exposed to blooms of the toxic dinoflagellate Pfiesteria have reported cognitive impairment lasting weeks or months. ${ }^{20}$ Cryptosporidium from animal waste and sewage has led to an increased number of beach closures, limiting the recreational opportunities for communities in the Bay watershed. ${ }^{21}$ Disproportionate environmental harms and the lack of water quality improvements undermine water quality trading programs and erode efforts to hold polluters accountable.

In the Bay, water quality trading will essentially move pollution from one water segment to another, concentrating pollution in some places while reducing it in others. Although the total amount of pollution should decrease, areas of high pollution concentration pose a risk of harmful localized nutrient loading, or "hot spots" of pollution. Not all pollution is created equally: "nutrient pollution" largely constitutes sewage, wastewater, and manure-all of which contain bacteria and pathogens such as fecal coliform, E.coli, and cryptosporidium; heavy metals and toxins; and antibiotics and other pharmaceutical products, in addition to the nitrogen, phosphorus, and sediment that suffocate the Bay. Excess nutrients in the Chesapeake also drive algal blooms that support the growth of toxic blue-green algae and other harmful pathogens.

To avoid hot spots and other environmental inequities, Bay state trading programs should implement geographic, seasonal, and general restrictions on trades.

Downstream trading, where a point source purchases credits from a seller downstream, can create unacceptably high levels of nutrient loading in the segment between the two sources. EPA should work with Bay states to prohibit downstream trading unless special approval is granted. Trading cannot threaten progress toward attainment of water quality

$\begin{array}{llllllllllllllllllllllllllllll}\text { C } & \text { E } & \mathbf{N} & \mathbf{T} & \mathbf{E} & \mathbf{R} & \mathbf{F} & \mathbf{O} & \mathbf{R} & \mathbf{P} & \mathbf{R} & \mathbf{O} & \mathbf{G} & \mathbf{R} & \mathbf{E} & \mathbf{S} & \mathbf{S} & \mathbf{I} & \mathbf{V} & \mathbf{E} & & \mathbf{R} & \mathbf{E} & \mathbf{F} & \mathbf{O} & \mathbf{R} & \mathbf{M}\end{array}$ 


\section{Water Quality Trading in the Chesapeake Bay}

standards, increase nutrient loading downstream of the purchaser, or cause exceedances in any segment.

EPA should also strictly adhere to section 122.4 of the CWA regulations to restrict trading that will cause or contribute to water quality violations. This may also require limiting the geographic or seasonal scope of trades, restricting the total amount of credits one source may purchase, reducing proposed trades, or even prohibiting certain trades outright. For example, runoff from agricultural lands is seasonal and may not coincide with seasonal pollutant extremes in the watershed. EPA and Bay states should also consider placing limits on certain pollutant forms that exert an acute effect (such as ammonia nitrogen), modifying NPDES permits to limit the amount of a facility's discharge that can be met through credits, or prohibiting trades above a certain amount or based on certain practices. ${ }^{22}$ When the risk of localized impacts exists, regulators should also retain the authority to prohibit or alter trades outright and instead require actual nutrient reductions at the source when there is a risk of localized impact.

EPA should also retract its tacit support for interstate trading in Section 10 of the Bay TMDL. ${ }^{23}$ Proposed interstate and interbasin trading raises concerns about the consistency of trading requirements across state lines, as well as the effectiveness of trading in unrelated basins and the potential for disparate impacts. Interstate trades should be generally prohibited unless reviewed and approved by agencies or a scientific panel. If Bay states continue to move forward on interstate trading, EPA should require that the most stringent rules apply when more than one state trading program is invoked in intersegment, or interbasin trades. EPA should require that the Bay states formally agree to such rules.

\section{Lessons from the Lower Boise River: Geographic Restrictions in NPDES Permits}

In the Lower Boise trading program, regulators issue modified NPDES permits that restrict the ability of individual point sources to engage in downstream trading. The Lower Boise program does not prohibit downstream trades but rather restricts the aggregate amount of downstream trading permitted. Regulators in the Chesapeake should also take care to ensure that downstream trading be considered in the aggregate, rather than on a permit-by-permit basis. While limited downstream trading may be permissible, with so much trading envisioned for the Chesapeake, it is feasible that too many individual downstream trades could be permitted without consideration for the aggregate impact.

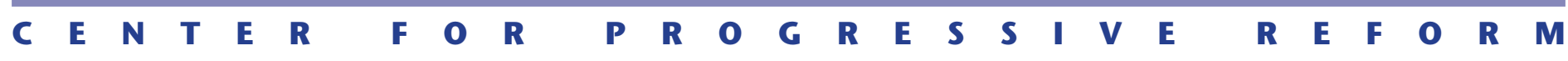




\section{Water Quality Trading in the Chesapeake Bay}

EPA and Bay states should terminate trades that result in hot spots, especially when such hot spots will disproportionately harm minority or low-income communities.

Health burdens and environmental harms are not shared equally, and low-income communities may be disproportionately impacted by potential hot spots created by trading. For example, low-income and minority communities in urban environments such as Baltimore may be unable to use other parts of the watershed for recreation or sustenance. In other parts of the watershed, many people draw water from wells that are contaminated with nitrates and bacteria from fertilizer, manure, and septic tanks. Those hazards hurt the poorest and most marginalized citizens because they often lack the financial resources or political influence to seek remedies.

To protect the most vulnerable populations within the watershed, the Bay states should provide mechanisms for restricting or terminating trades that create hot spots.

EPA and Bay states should consider environmental justice concerns and other equity impacts when establishing trading programs and approving individual trades.

The environmental justice movement recognizes that every person should have equal access to a healthy environment and some minimum level of natural resources to pursue a safe, purposeful, and dignified existence. ${ }^{24}$ A commitment to environmental justice in nutrient trading programs requires that policy makers ensure full and fair participation in all trading decisions that affect poor and minority communities. Regulators and government agencies must also guarantee that poor and minority communities do not experience any disproportionate delay or reduction in receiving any benefits of trading, such as income from credit-generating activities or aesthetic benefits from green spaces that help retain stormwater runoff.

\section{Principle 3: A rigorous, accountable trading program relies on strong oversight and vigorous enforcement to ensure actual pollution reductions.}

If trading goes forward in the capacity envisioned by its supporters, neither EPA's nor Bay states' current regulatory apparatus will be sufficiently robust or solvent to handle the volume. EPA and Bay states will need to seek considerable additional resources to appropriately manage trading in a way that is fair, trustworthy, and effective. EPA and Bay states must also ensure that trading programs and their participants remain legally accountable for their trades, including for failed reductions and fraudulent trades, if genuine reductions are to be made.

EPA should exercise its oversight authority under the CWA to ensure that trading programs help Bay states achieve water quality standards and

$\begin{array}{llllllllllllllllllllllllllll}\text { C } & E & \mathbf{N} & \mathbf{T} & \mathbf{E} & \mathbf{R} & & \mathbf{F} & \mathbf{O} & \mathbf{R} & \mathbf{P} & \mathbf{R} & \mathbf{O} & \mathbf{G} & \mathbf{R} & \mathbf{E} & \mathbf{S} & \mathbf{S} & \mathbf{I} & \mathbf{V} & \mathbf{E} & & \mathbf{R} & \mathbf{E} & \mathbf{F} & \mathbf{O} & \mathbf{R} & \mathbf{M}\end{array}$ 


\section{Water Quality Trading in the Chesapeake Bay}

the Bay TMDL and should require states to develop contingency plans that specifically address shortcomings in the proposed trading programs and outcomes.

Consistent and substantial federal regulatory oversight is key for trading programs to succeed. Indeed, the CWA entrusts EPA with the ultimate responsibility to administer and oversee the health and vitality of the nation's waters, and EPA must fully exercise that responsibility. Although EPA has published some guidance on water quality trading, the guidance is extremely weak, filled with vague, non-binding suggestions, and explicitly articulates the agency's detached approach to trading. ${ }^{25}$ EPA should expand and improve upon existing guidance as well as emphasize the importance of the requirements established in Appendix S of the Bay TMDL.

As a federal agency, EPA is uniquely poised and explicitly tasked to protect public health and the environment by holding Bay states accountable for achieving their pollution reductions. The agency cannot do this by merely consulting with Bay states. EPA must strictly and deliberately oversee Bay states' trading programs.

EPA and Bay states should ensure that trades are enforceable by either incorporating trade terms into the NPDES permit of a point source or memorializing the trade terms in a contract that allows EPA or the state to enforce the contract.

To ensure that trading regimes are legally accountable, a mechanism must be in place to allow regulators to enforce the terms of nutrient trades. To that end, EPA should mandate that state permit writers incorporate trade transactions into NPDES permits held by the point source seeking to buy or sell credits. If no regulated entity with a permit is involved in the trade, EPA should require that trades be memorialized in a contractual instrument that is enforceable by a state agency or EPA. This could be accomplished by naming EPA or the state agency as a third party beneficiary, for example.

EPA and Bay states must take credible, consistent, and meaningful enforcement actions to deter future violations.

EPA and Bay states must remain willing to consistently and effectively impose penalties on sources whose discharges exceed their permits limits or credit allocations. In the trading context, demand for credits is only as strong as the threat of enforcement to comply with pollution reduction targets. If the regulated community does not believe it will face real punishment for violations of trading agreements or permit requirements, demand for credits will falter and water quality will not improve.

If the regulated community views enforcement as both unlikely and, when implemented, weak, it has little incentive to comply with the CWA. The same goes for trading. If noncompliance becomes the status quo, demand will plummet as regulated entities opt to delay upgrades and ignore their pollution reduction obligations rather than pay for

$\begin{array}{llllllllllllllllllllllllllllll}C & \mathbf{E} & \mathbf{N} & \mathbf{T} & \mathbf{E} & \mathbf{R} & & \mathbf{F} & \mathbf{O} & \mathbf{R} & \mathbf{P} & \mathbf{R} & \mathbf{O} & \mathbf{G} & \mathbf{R} & \mathbf{E} & \mathbf{S} & \mathbf{S} & \mathbf{I} & \mathbf{V} & \mathbf{E} & & \mathbf{R} & \mathbf{E} & \mathbf{F} & \mathbf{O} & \mathbf{R} & \mathbf{M}\end{array}$




\section{Water Quality Trading in the Chesapeake Bay}

credits. Recent statistics on nationwide CWA enforcement are dispiriting: between 2004 and 2007, the New York Times found that CWA violations nationwide grew 16 percent. During the same period, enforcement was alarmingly low: fewer than 3 percent of CWA violations resulted in fines or other significant punishments. ${ }^{26}$ These statistics support the link between lax enforcement and a willingness on the part of companies to ignore the law.

\section{Citizen Suit Enforcement}

Citizen suit enforcement is another type of enforcement and oversight that can supplement EPA and state efforts to catch violations that harm public health and the environment. Citizen suit enforcement will be difficult to pursue for water quality trading because it is not explicitly authorized in the CWA, nor do Bay states include citizen suit enforcement in their trading programs. As discussed above, Bay states and EPA should work together to extend citizen suit provisions to trading.

\section{Conclusion}

EPA and Bay states should commit to evaluating not how but whether trading will work for the Chesapeake. Too often, evaluations of water quality trading have been based on the assumption that trading activity will happen. The many obstacles to successful trading programs mean that regulators and politicians should be honest and realistic about the goals and potential outcomes. Bay states and EPA must focus on environmental improvement, and recognize, explicitly, that trading is but one tool among many. Several recent evaluations of water quality trading have made clear that trading alone may not be sufficient. And if trading does not work, the Chesapeake cannot be left to wallow. For example, the trading program in the Cherry Creek Basin in Colorado experienced only 90 pounds of traded phosphorous over more than ten years, and water quality remains impaired. ${ }^{27}$

As proposed, many of the Bay states' programs are missing the rigor required of a successful trading program. Some Bay states, like Pennsylvania, are allowing trading to move forward too quickly without sufficient consideration for successful design or real accountability. EPA and citizens concerned about the health of the Bay should critically monitor Bay states as these programs develop. Without the components outlined here to protect water quality and human health, trading should be merely one tool for achieving the Bay TMDL and should not overshadow efforts to control pollutant discharge through more stringent NPDES permits or regulation of the major sectors that pollute the Bay. EPA and the Bay states should also commit to re-evaluating the trading programs every year and be prepared to implement other tools immediately if trading activity fails to materialize. Ultimately, trading must prove its worth by producing real pollutant reductions that lead to measurable and verifiable improvements in the Chesapeake Bay.

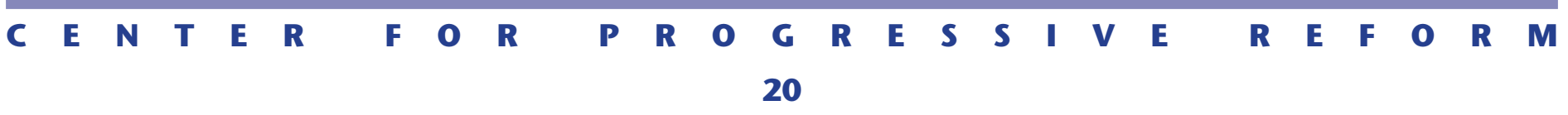




\section{Water Quality Trading in the Chesapeake Bay}

\section{Endnotes}

1 U.S. EPA, Final Chesapeake Bay Total Maximum Daily Load for Nitrogen, Phosphorus, and Sediment (Dec. 29,2010) [hereinafter BAY TMDL]; Clean Water Act Section 303(d): Notice for the Establishment of the Total Maximum Daily Load (TMDL) for the Chesapeake Bay, 76 Fed. Reg. 549 (Jan. 5, 2011).

2 Maryland, Pennsylvania, and Virginia all have legislation or other measures in effect to support trades between two point sources and between a nonpoint source credit-seller and a point source credit-buyer. West Virginia, Delaware, and New York have partial measures in place to support trades or offsets between two point sources. The District of Columbia does not have any trading programs in place. See U.S. EPA, Reviews of Bay JuRisdictions' Trading and Offset Programs (Dec. 2011), available at http://www. epa.gov/reg3wapd/pdf/pdf_chesbay/Phase2WIPEvals/Trading Offsets/PortfolioOfReports.pdf.

3 Industrial Economics, EPA Water Quality Assessment at ES-1 (2008) ("EPA has been undertaking these activities at the headquarters and regional level for over a decade [yet] ... only 100 facilities have participated in trading, and 80 percent of trades have occurred within a single trading program.”).

4 See Mark O. Ribaudo \& Jessica Gottlieb, Point-Nonpoint Trading - Can It Work?, 47 J. AM. WATER Res. Assn. 5, 6 (2011); see also Dennis M. King \& Peter J. Kuch, Will Nutrient Credit Trading Ever Work? An Assessment of Supply and Demand Problems and Institutional Obstacles, 33 Env. L. REP. 10352 (2011).

5 BAY TMDL, APPENDIX S, supra note 1; U.S. EPA, WATER QUALITY Trading Toolkit for Permit-Writers (2009); U.S. EPA, Water Quality Trading Assessment Handbook: Can Water Quality Trading Advance Your Watershed's Goals? (2004) [hereinafter EPA Handbook]; U.S. EPA, Water Quality Trading Policy (2003).

6 Cy Jones, et Al., World Resources Institute, How Nutrient Trading Could Help Restore the Chesapeake Bay (2010).

7 See, e.g., Industrial Economics, EPA Water Quality Assessment supra note 3 .

8 Ribaudo \& Gottlieb, supra note 4, at 6.

9 See sources cited supra note 5.

10 Robert L. Glicksman \& Yee Huang, Failing the Bay: Clean Water Act Enforcement in Maryland Falling Short, CPR White Paper No. 1004 (April 2010).

${ }_{11} \quad I d$.

1233 U.S.C. $§ 1313$ (c)(2)(A) ("revised or new water quality standard shall consist of the designated uses of the navigable waters involved and the water quality criteria for such waters based upon such uses.”); see also 40 C.F.R. 131.10(a) (designated uses must include fishable and swimmable).
1333 U.S.C. $\S 1314$.

14 U.S. EPA, Nutrient Pollution and Numeric Water Quality Standards (2007), available at http://www.epa.gov/waterscience/criteria/ nutrient/policy.html.

15 See U.S. EPA, State Development of Numeric Criteria for Nitrogen and Phosphorus Pollution, available at http://water.epa.gov/ scitech/swguidance/standards/criteria/nutrients/progress.cfm.

16 U.S. EPA, Basic Course: Key Concepts (Module 3.E), Forms of EXPRESSION: Numeric AND NarRative CRITERIA, available at http:// water.epa.gov/learn/training/standardsacademy/mod3/page6.cfm.

17 Maryland Code, Title 26, Subtitle 8, Chapter 2, Regulation .03, Surface Water Quality Criteria, available at http://www.dsd.state. md.us/comar/comarhtml/26/26.08.02.03.htm.

18 Christoph M. Gross et al., Nitrogen Trading Tool to Facilitate Water Quality Credit Trading, 63 J. SoIL \& WATER Cons. 44A (2008); see also Jorge A. Delgado et al., Assessment of Nitrogen Losses to the Environment with a Nitrogen Trading Tool (NTT), 63 COMPUTERs \& ElECtronics IN Ag. 193 (2008).

19 ChesapeakeStat, TMDL Tracking, http://stat.chesapeakebay. net $/$ ? $\mathrm{q}=$ node/130\&quicktabs_10 $=3$.

20 J. Glenn Morris, Jr., Human Health Effects and Pfiesteria Exposure: A Synthesis of Available Clinical Data, 109 ENvTL. Health Perspectives 787, 789 (2001); Jonathan Bor \& Caitlin Francke, Memory Loss Led to Human, Toxin Link; Pfiesteria Affects Brain, Scientists Say, Baltimore Sun, Aug. 31, 1997.

21 Chesapeake Bay Foundation, Bad Water 2009: The Impact on Human Health in the Chesapeake Bay Region 1, 10 (2009).

22 EPA HANDBOOK, supra note 5, at 55.

23 Bay TMdL, Section 10, Implementation and Adaptive Management, supra note 1 at 10-3.

24 Robert M. Verchick, Facing Catastrophe: Environmental Action in a Post-Katrina Word 118 (2010).

25 See sources cited supra note 5 .

26 Charles Duhigg, Clean Water Laws Are Neglected, at a Cost in Suffering, New York Times, Sep. 13, 2009, at A1.

27 Ann Powers, The Current Controversy Regarding TMDLs: Contemporary Perspectives "TMDLS and Pollutant Trading," 4 VT. J. ENVTL. L. 1 (2003).

$\begin{array}{llllllllllllllllllllllllllllll}C & E & N & \text { T } & \text { E } & \text { R } & & \text { F } & \text { O } & \text { R } & & \text { P } & \text { R } & \text { O } & \text { G } & \text { R } & \text { E } & \text { S } & \text { S } & \text { I } & \text { V } & \text { E } & \text { R } & \text { E } & \text { F } & \text { O } & \text { R } & M\end{array}$




\section{Water Quality Trading in the Chesapeake Bay}

\section{About the Center for Progressive Reform}

Founded in 2002, the Center for Progressive Reform is a 501(c)(3) nonprofit research and educational organization comprising a network of scholars across the nation dedicated to protecting health, safety, and the environment through analysis and commentary. CPR believes sensible safeguards in these areas serve important shared values, including doing the best we can to prevent harm to people and the environment, distributing environmental harms and benefits fairly, and protecting the earth for future generations. CPR rejects the view that the economic efficiency of private markets should be the only value used to guide government action. Rather, CPR supports thoughtful government action and reform to advance the well-being of human life and the environment. Additionally, CPR believes people play a crucial role in ensuring both private and public sector decisions that result in improved protection of consumers, public health and safety, and the environment. Accordingly, CPR supports ready public access to the courts, enhanced public participation, and improved public access to information.

CPR is grateful to the Town Creek Foundation for funding this briefing paper.

This white paper is a collaborative effort of the following individuals: Rena Steinzor, Professor of Law at the University of Maryland Francis King Carey School of Law and President of CPR, Nick Vidargas, Policy Analyst at CPR, Shana Jones, Senior Consultant, and Yee Huang, Policy Analyst at CPR. The authors gratefully acknowledge the assistance of Jake Caldwell, Executive Director of CPR, and, Matthew Freeman, Media Consultant. The authors bear responsibility for any factual errors and for the views and recommendations expressed in this paper.

www.progressivereform.org

For media inquiries, contact Matthew Freeman at mfreeman@progressivereform.org or Ben Somberg at bsomberg@progressivereform.org.

For general information, email info@progressivereform.org.

(C) 2012 Center for Progressive Reform.

$\begin{array}{lllllllllllllllllllllllllll}C & E & N & T & E & R & & F & O & R & \text { P } & R & \text { O } & \text { G } & R & \text { E } & \text { S } & \text { S } & \text { I } & \text { V } & \text { E } & \text { R } & \text { E } & \text { F } & \text { O } & \text { R } & M\end{array}$


To see more of CPR's work or to contribute, visit CPR's website at www.progressivereform.org.

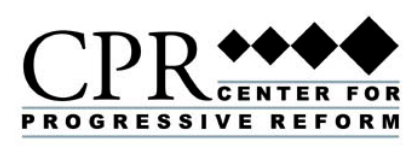

RETURN UNDELIVERABLES TO:

Center for Progressive Reform

455 Massachusetts Avenue, NW

\# 150-513

Washington, DC 20001 